\title{
An Improved Surgical Technique for Pterygium Excision With Intraoperative Application of Mitomycin - C
}

Ophthalmic Surg Lasers 1998;29:685-7.

Marisa B. Potério, Milton R. Alves, José A. Cardillo, Newton K. José

Abstract: A surgical technique was designed to improve safety after pterygium excision with intraoperative application of mitomycin-C (MMC). A limbic incision was performed in 40 eyes. The body of the pterygium was dissected from the episclera to allow its excision. Care was taken to avoid excessive delamination and cauterization of tissues. A $0.02 \%$ MMC solution was then applied. Only at the end of the surgery was the head of the pterygium dissected from the cornea. The 8-0 absorbable sutures were used to place both edges of the conjunctiva together to completely cover the area of bare sclera. After a mean follow-up time of 12 months, a recurrence rate of $5 \%$ was observed. No complications of therapy were observed. This is a logical alternative to other surgical techniques. However, randomized studies with more patients and longer follow-up are necessary to determine the potential of this procedure in improving the safety of pterygium excision with intraoperative MMC.

\section{Pattern reversal visual evoked response in retinitis pigmentosa}

Documenta Ophthalmologica 1999; 96: 321-31.

\author{
Flavio R. L. Paranhos, Osamu Katsumi, Miki Arai, Marcio B. Nehemy, Tatsuo Hirose
}

Purpose: To determine if the pattern reversal visual evoked response (PVER) can objectively evaluate visual function in retinitis pigmentosa $(\mathrm{RP})$.

Methods: We retrospectively reviewed the medical records of 29 patients ( 29 eyes) with RP, a visual acuity (VA) better than 20/100, and for whom an electroretinogram (ERG) and a PVER had been recorded. A steady-state PVER was measured using five check sizes: 160, 80, 40, 20 and 10 min of arc. The best-corrected VA was measured using the ETDRS chart. Visual fields (VFs) were measured using standard Goldmann perimetry. To quantify the VFs, we measured the field size (isopter IV - 2) in four meridians and averaged them. Twenty-five eyes of 25 normal subjects served as controls.
Results: The mean and median VAs were 20/40 (logMAR $=$ $0.30 \pm 0.20$ ). The average VF (isopter IV - 2) was $20^{\circ}$ (median, $9^{\circ}$; range, $2^{\circ}$ to $\left.62^{\circ}\right)$. All patients had a recordable PVER. Only $12(41 \%)$ patients had recordable ERGs, all subnormal. The PVER amplitudes showed a relatively good correlation with $\mathrm{VA}$ in the intermediate check sizes (40 min of arc, $\mathrm{r}=0.611$, $\mathrm{P}=0.0004 ; 20 \mathrm{~min}$ of arc, $\mathrm{r}=0.596, \mathrm{p}=0.007)$. The PVER amplitude-check size function had a flattened inverted $\mathrm{V}$ shape in the RP patients and an inverted $U$ shape in the normal subjects, with the mean amplitudes for the RP patients significantly smaller than the normals at all check sizes.

Conclusion: The PVER is a useful method for objectively evaluating the visual function in RP patients whose central vision is still preserved. 


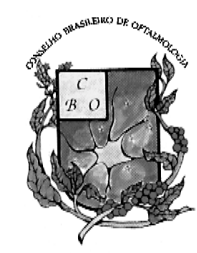

CONSELHO BRASILEIRO DE OFTALMOLOGIA

\title{
$14^{\circ}$ Congresso Brasileiro de Prevenção da Cegueira e Reabilitação Visual
}

\author{
6 a 9 de setembro de 2000 \\ Centro de Convenções de Natal - Natal/RN
}

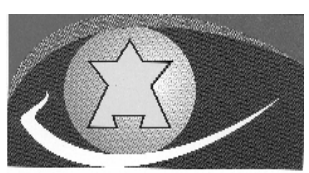

1 - CONGRESSO BRASILEIRO ERPABILITACAOAO VISLIAL

\section{NORMAS PARA ENVIO DE TRABALHOS DATA LIMITE PARA ENVIO: 12/05/2000}

1. Somente poderão ser inscritos trabalhos:

a) Não publicados em periódicos ou livros no Brasil ou no exterior (até a data da postagem do trabalho);

b) Não previamente apresentados em congressos de abrangência nacional;

c) Com 05 (cinco) autores no máximo.

2. Os trabalhos poderão ser apresentados oralmente (temas livres) ou sob a forma de pôsteres, não podendo um mesmo trabalho ser apresentado sob as duas formas.

3. Temas livres ou pôsteres deverão ser enviados na íntegra (não serão aceitos só resumos) para a Secretaria Executiva do Congresso - CBO Eventos, Alameda Santos, $1.343-11^{\circ}$ andar, CEP 01419-001, São Paulo, SP.

4. Data-limite para o envio dos trabalhos é 12 de maio de 2000 (data do carimbo da postagem do correio).

5. 0 texto deverá ser datilografado ou impresso por computador, em português, espaço duplo, papel ofício, numa face só com o corpo de letra tamanho 12.

6. Somente serão apreciados pela Comissão Científica os trabalhos que também apresentarem literatura nacional pertinente ao trabalho enviado, independentemente de seu mérito intrínseco. As fontes de informação da literatura oftalmológica brasileira são: Arquivos Brasileiros de Oftalmologia e Revista Brasileira de Oftalmologia. 0 trabalho deverá conter título e resumo em português e inglês (mencionar o serviço e cidade da coleta de dados). Em português, são obrigatórios ainda os itens: introdução, material e métodos, resultados, discussão e referências bibliográficas. Estas últimas deverão obedecer às normas do "Index Medicus" ou "World Medical Periodical", e não exceder o número de 20 (vinte).

7. Embora trabalhos realizados no exterior possam ser considerados para apresentação, só poderão concorrer a "premiação", os trabalhos em que a coleta de dados, experimentos, ou relato de caso, foram realizados no Brasil, exceto para o prêmio Latino - americano.

8. Os trabalhos deverão conter no máximo 10 (dez) páginas, 5 (cinco) tabelas e 3 (três) figuras.

9. Constar de 3 (três) cópias, admitindo-se fotocópias (coloridas para figuras coloridas).

10. Em folha separada deverá constar:
a) título do trabalho;
b) nome(s) do(s) autor(es);
c) endereço completo;
e) assinatura do(s) autor(es);
f) opção por tema livre ou pôster;
d) instituição onde foi realizado o trabalho;
g) classificação em uma das categorias abaixo:

Categoria Geral (que corresponderá ao prêmio ao qual o trabalho estará concorrendo):
- Oftalmologia Clínica
- Pesquisa Básica (laboratorial ou animal)
- Oftalmologia Cirúrgica

Área específica da oftalmologia a que o trabalho pertence:

- Catarata

- Neuroftalmologia

- Cirurgia Refrativa

- Órbita

- Refração

- Córnea

- Patologia Externa

- Estrabismo

- Plástica Ocular / Vias Lacrimais

- Genética

- Prevençáo da Cegueira

- Lentes de Contato

- Propedêutica

- Retina

- Trauma

- Tumores

- Uveítes / AIDS

- Visão Sub-Normal

11. Apresentação de casos clínicos serão aceitos apenas excepcionalmente. Não serão aceitos trabalhos de revisão de literatura.

12. Os trabalhos não serão devolvidos.

Regulamento para os Prêmios:

Os melhores trabalhos receberão prêmios nas seguintes categorias:
a) "Prêmio Conselho Brasileiro de Oftalmologia" - dado ao melhor trabalho;
b) "Prêmio Oftalmologia Cirúrgica"
d) "Prêmio Pesquisa Básica" - laboratorial ou animal
c) "Prêmio Oftalmologia Clínica"
e) "Prêmio Regional (Norte, Nordeste, Sul, Sudeste, Centro- Oeste)
f) "Prêmio Latino-americano" (excluindo Brasil)

\section{INFORMAÇÕES: CBO Eventos}

Al. Santos, 1343 / Conj. 1110 - CEP: 01419-001 - São Paulo - SP • Tel: 1132664000 / Fax: 1131710948 / Email: eventos@cbo.com.br 